\title{
Exacerbation frequency and FEV1 decline of COPD: is it geographic?
}

\author{
Terence A.R. Seemungal ${ }^{1}$ and Jadwiga A. Wedzicha²
}

Affiliations: 'Dept of Clinical Medical Sciences, St Augustine Campus, University of the West Indies, St Augustine, Trinidad and Tobago. ${ }^{2}$ National Heart and Lung Institute, Imperial College London, London, UK.

Correspondence: J.A. Wedzicha, National Heart and Lung Institute, Royal Brompton Campus, Imperial College London, London SW3 6LR, UK. E-mail: j.wedzichađimperial.ac.uk

○ @ERSpublications

All exacerbation data, whether reported, self-managed or untreated, is required to recognise health burdens in COPD http://ow.ly/usGyB

Chronic obstructive pulmonary disease (COPD) exacerbations are episodes of symptom worsening that have major impacts on a variety of health outcomes, including quality of life, hospital admission and death [1]. Exacerbation reduction is now a key outcome for pharmacological therapies in COPD and, thus, if exacerbation can be prevented how does this affect disease progression and lung function decline?

The issue of the importance of lung function decline in COPD first arose when FlETCHER and PETo [2] explored lung function in a cohort of 792 male British postal workers. These subjects were studied over 8 years and it was found that exacerbations were associated with the ratio of forced expiratory volume in $1 \mathrm{~s}$ (FEV1) to the cube of the height, although the exacerbation definition was limited at that time. This work was followed in close succession by a study from Utah in which KANNER et al. [3] showed that exacerbation frequency was related to COPD severity, thus implicating exacerbation frequency as a factor in FEV1 decline. However, detecting the relationship proved elusive until the Lung Health Study showed that in smokers and intermittent quitters each additional exacerbation reported to physicians caused a greater annual decline of $7 \mathrm{~mL}$ [4]. The following year, the London COPD cohort study reported that in patients with a history of more frequent exacerbations there was an increased rate of decline of $8 \mathrm{~mL}$ per year compared with infrequent exacerbators [5]. The relationship between exacerbation frequency and FEV1 decline in COPD has also been seen in the UPLIFT study [6] and another study from Greece [7]. All of these studies were performed on European or North American subjects with COPD.

In diseases other than COPD, an occasional relationship has been reported between exacerbation rates and FEV1 decline. In a study of asthmatics over a period of 11 years, a relationship was seen between exacerbation frequency and FEV1 decline [8]. In a Canadian study, WATERS et al. [9] showed that severe cystic fibrosis exacerbations (requiring hospitalisation) were associated with greater FEV1 decline. Although the European Cystic Fibrosis Society study did not report on exacerbations they have reported a link between chronic Pseudomonas aeruginosa infection (a known risk factor for cystic fibrosis exacerbations) and FEV1 decline [10], from which such a relationship may be inferred and this supports the findings of the Canadian study.

In this issue of the European Respiratory Journal, the relationship between exacerbations and lung function decline is addressed in a cohort of 279 Japanese subjects followed over a 5-year period in Hokkaido [11]. The detection rate for exacerbations in this study was 0.78 events per year using a symptom-based definition. The study found no significant relation between exacerbation rate and FEV1 decline. The annual decline in FEV1 in the Hokkaido study was $32 \mathrm{~mL} \cdot \mathrm{year}^{-1}$ similar to that found in the London COPD study [5] and somewhat less than that observed in the Lung Health study $\left(\sim 45 \mathrm{~mL} \cdot \mathrm{year}^{-1}\right)$ [4]. Thus, it is unlikely

Received: March 102014 | Accepted after revision: March 102014

Conflict of interest: Disclosures can be found alongside the online version of this article at www.erj.ersjournals.com

Copyright @ERS 2014 
that the lack of a relationship between FEV1 decline and exacerbation rates in the Hokkaido study was due to a milder progression of COPD in subjects from Hokkaido.

There has been much written about definitions of COPD exacerbations and their frequencies; generally the more closely subjects are followed, the higher the exacerbation rates observed. Support for this comes from several studies but we need only consider a few cohort studies of over 100 patients. MonTo et al. [12] followed 142 patients by weekly telephone calls and found an exacerbation rate of 2.33 events per year, but ANTHONISEN et al. [13] followed 173 patients and found a rate of 1.3 events per year relying on 3 monthly patient recall. The London COPD study using monthly visits and daily diary cards found an average rate of 2.9 exacerbations per year [5]. In China, a study of carbocisteine using a diary cards for exacerbation detection and using the Anthonisen definition for an exacerbation, found mean exacerbation rates of 1.01 and 1.35 per year in the two arms of the study that are not much greater than those reported in the Hokkaido Study [14]. However, with close follow-up and daily monitoring XU et al. [15] have reported, from China, an exacerbation rate of about 2 events per year with $\sim 50 \%$ not reported to physicians. This nonreporting rate of at least $50 \%$ for COPD exacerbations was first observed by the London COPD study [16]. The recent SPARK study of inhaled dual bronchodilation in prevention of COPD exacerbations used electronic daily diaries to aid exacerbation detection and the study reported high total exacerbation rates [17].

Despite numerous studies no reproducible differences have been found between reported and unreported exacerbations. One study has reported that the greater the number of unreported exacerbations the worse the quality of life score and the greater the risk of hospital admission [18]. Thus, unreported exacerbations constitute a clear source of health burden in COPD. In the Hokkaido study exacerbations were detected by reply-paid postcards. The response rate for these cards was very high $(>99 \%)$, but the questions on the postcard appeared only to allow for patient recall of events. Only if an event was suspected was a telephone call made to the patient and this would have occurred well after the event, requiring patient recall of the event. Thus, there was no daily monitoring of exacerbation symptoms in this study and it is, therefore, not surprising that the event rates were so low.

The TORCH study was the first international study to consider COPD exacerbation rates between northern, southern and tropical countries [18]. There was an apparent difference between communities in exacerbation rates and this suggests, along with the Hokkaido study, that there are geographic differences in exacerbation rate. While this may be so the difference may well be much smaller than anticipated when unreported exacerbations are taken into account. It is now time to collect all exacerbation events, whether reported, self-managed or untreated, so that we can recognise the true health burden of exacerbations in COPD patients.

\section{References}

Wedzicha JA, Seemungal TAR. COPD exacerbations: defining their cause and prevention. Lancet 2007; 370: 786-796. Fletcher EC, Peto R. The natural history of chronic airflow obstruction. Br Med J 1977; 1: 1645-1648.

Kanner RE, Renzetti AD Jr, Klauber MR, et al. Variables associated with changes in spirometry in patients with obstructive lung diseases. Am J Med 1979; 67: 44-50.

4 Kanner RE, Anthonisen NR, Connett JE. Lower respiratory illnesses promote FEV1 decline in current smokers but not ex-smokers with mild chronic obstructive pulmonary disease. Am J Respir Crit Care Med 2001; 164: 358-364. Donaldson GC, Seemungal TAR, Bhowmik A, et al. Relationship between exacerbation frequency and lung function decline in chronic obstructive pulmonary disease. Thorax 2002; 57: 847-852.

6 Halpin DM, Decramer M, Celli B, et al. Exacerbation frequency and course of COPD. Int J Chron Obstruct Pulmon Dis 2012; 7: 653-661.

7 Makris D, Moschandreas J, Damianaki A, et al. Exacerbations and lung function decline in COPD: new insights in current and ex-smokers. Respir Med 2007; 101: 1305-1312.

8 Bai TR, Vonk JM, Postma DS, et al. Severe exacerbations predict excess lung function decline in asthma. Eur Respir J 2007; 30: 452-456.

9 Waters V, Stanojevic S, Atenafu EG, et al. Effect of pulmonary exacerbations on long-term lung function decline in cystic fibrosis. Eur Respir J 2012; 40: 61-66.

10 Kerem E, Viviani L, Zolin A, et al. Factors associated with FEV1 decline in cystic fibrosis: analysis of the data of the ECFS Patient Registry. Eur Respir J 2014; 43: 125-133.

11 Suzuki M, Makita H, Ito YM, et al. Clinical features and determinants of COPD exacerbation in the Hokkaido COPD cohort study. Eur Respir J 2014; 43: 1289-1297.

12 Monto AS, Higgins MW, Ross HW. The Tecumseh study of respiratory illness. VIII. Acute infection in chronic respiratory disease and comparison groups. Am Rev Respir Dis 1975; 111: 27-36.

13 Anthonisen NR, Manfreda J, Warren CP, et al. Antibiotic therapy in exacerbations of chronic obstructive pulmonary disease. Ann Intern Med 1987; 106: 196-204.

14 Zheng JP, Kang J, Huang SG, et al. Effect of carbocisteine on acute exacerbation of chronic obstructive pulmonary disease (PEACE Study): a randomised placebo-controlled study. Lancet 2008; 371: 2013-2018.

$15 \mathrm{Xu} \mathrm{W}$, Collet J-P, Shapiro S, et al. Negative impacts of unreported COPD exacerbations on health-related quality of life at 1 year. Eur Respir J 2010; 35: 1022-1030.

16 Seemungal TA, Donaldson GC, Paul EA, et al. Effect of exacerbation on quality of life in patients with chronic obstructive pulmonary disease. Am J Respir Crit Care Med 1998; 157: 1418-1422. 
17 Wedzicha JA, Decramer M, Ficker JH, et al. Analysis of chronic obstructive pulmonary disease exacerbations with the dual bronchodilator QVA149 compared with glycopyrronium and tiotropium (SPARK): a randomised, doubleblind, parallel-group study. Lancet Respir Med 2013; 1: 199-209.

18 Wilkinson TMA, Donaldson GC, Hurst JR, et al. Early therapy improves outcomes of exacerbations of chronic obstructive pulmonary disease. Am J Respir Crit Care Med 2004; 169: 1298-1303.

19 Jenkins CR, Celli B, Anderson JA, et al. Seasonality and determinants of moderate and severe COPD exacerbations in the TORCH study. Eur Respir J 2012; 39: 38-45. 